\title{
THE TOXICITY OF TRIMETHYLAMINE FOR NECROPHORUS ORBICOLLIS (SAY).
}

\author{
By CyrIL E. ABвotT
}

Morgan Park, Ill.

As a natural decomposition product of flesh, trimethylamine $\left[\mathrm{N}\left(\mathrm{CH}_{3}\right)_{3}\right]$, is found, in varying concentrations, in those animal remains to which various necrophilous beetles are attracted. It is of some interest to know, then, how well a species such as Necrophorus orbicollis can withstand the toxic effects of this chemical.

For testing the resistance of the beetle to various concentrations of the substance a glass jar with a hollow, groundglass stopper was used. The jar had a capacity of $125 \mathrm{cc}$; the hollow in the stopper $5 \mathrm{cc}$. The stopper was stuffed tightly with cotton, which was then soaked with all the solution it would contain without dripping. The jar was cleaned with hot water, the stopper replaced, and the whole allowed to stand for 1 minute before the specimen was introduced. The beetle was thus exposed to the chemical in its gaseous form.

The insects used were active adults, and, although but one specimen was used at a time, each experiment was repeated with two additional beetles, so that an average could be determined; this was necessary because individuals varied in size. The data on any specimen showing an unusually long or short period, as compared with the other two specimens, was discarded; the average then being taken from the two remaining.

It is somewhat difficult to determine the exact deathpoint for the Necrophori. Preliminary experiments indicated that although parts of the body may move for hours, beetles in which not more than one tarsus twitched spasmodically never recovered after removal from the jar; this was considered the "death-point," and the time elapsing 
between the introduction of the insect into the jar and this point constituted the time necessary to produce death.

The stock solution of trimethylamine had a concentration of $33 \%$. It is doubtful if a greater concentration than this ever occurs in nature. Dilutions of the stock solution with water were used for the remaining tests.

By making a few progressive records of the action of the chemical on the beetles, paralysis was found to occur in the following order:

1. Paralysis of posterior legs.

2. Paralysis of middle legs.

3. Paralysis of anterior legs. (This followed so closely upon that of the middle legs that in concentrated atmospheres the time interval could not be determined.)

4. Paralysis of antennæ.

5. Paralysis of mouth-parts (practically all at once).

6. Spasmodic twitching of tarsi and tip of abdomen.

7. Slow movements of legs and head. hours.)

8. Movement of abdomen only. (May continue for many

9. All movement ceases.

The time durations necessary to bring about death at various concentrations of trimethylamine were as follows:
$33 \%$ - 5 minutes
$10 \%-22$ minutes
$25 \%$ - 7 minutes
$5 \%-40$ minutes
$20 \%$ - 10 minutes
$1 \%-70$ minutes

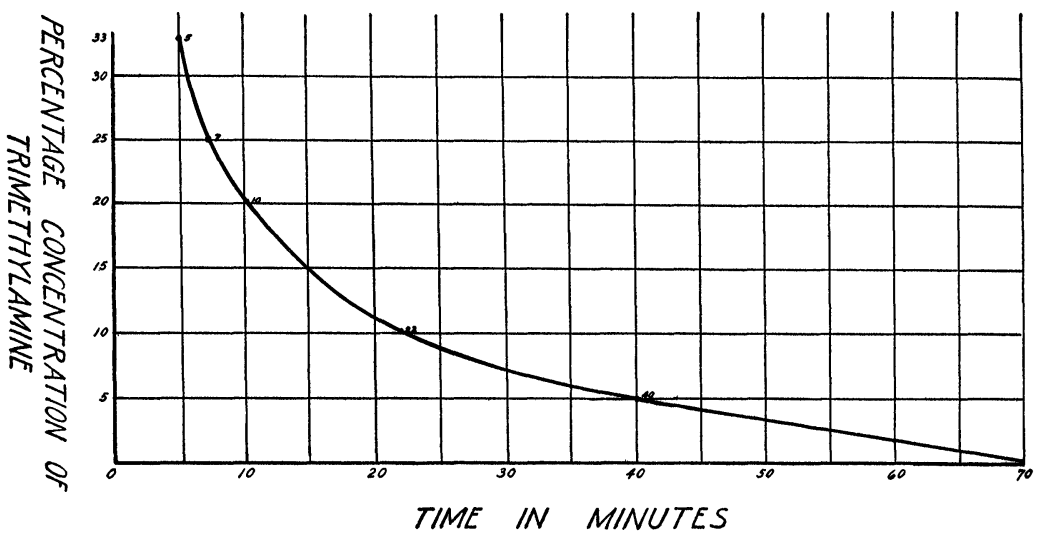

FIG. 1. Toxicity of trimethylamine for Necrophorus orbicollis. 
The graph (Fig. 1) indicates a little more clearly the relation between toxicity and the various concentrations of the chemical. It appears that at high concentrations death occurs very rapidly, but that as the concentration decreases the toxicity becomes less. Moreover, the toxicity decreases, not in direct proportion to the concentration, but in a kind of geometric proportion. At very low concentrations (1\%) the beetles can withstand the fumes for a long time.

The objection may be raised that the data here given do not represent the toxicity of given concentrations of substance, but the time required for the substance to reach a toxic concentration in an inclosed space. But this is chiefly an academic objection. If seventy minutes are required for a $1 \%$ solution of trimethylamine to fill $125 \mathrm{cc}$. of space with enough gas to kill a beetle, the result is practically the same as if a low concentration, held constant, brought about the same result. The effect is the same in either case.

There is some indication that, in low concentrations, trimethylamine actually attracts Necrophori. Several specimens kept in an experimental cage, were trapped twice as frequently with this as with pure water. Beetles also tore a piece of cotton soaked with the chemical and left in their cage.

Dead bodies lying in the open must be comparatively free from high concentrations of so volatile a substance as trimethylamine. In a confined space the situation is different. It is the custom of collectors to trap necrophilous beetles in jars sunk in the earth and containing scrap meat. In such jars Necrophori, as well as other beetles, are often found dead, even when the decaying flesh is not sufficiently liquified to produce drowning. Such jars have a strong odor of ammonia, which doubtless, in many cases, is due to the presence of trimethylamine. 

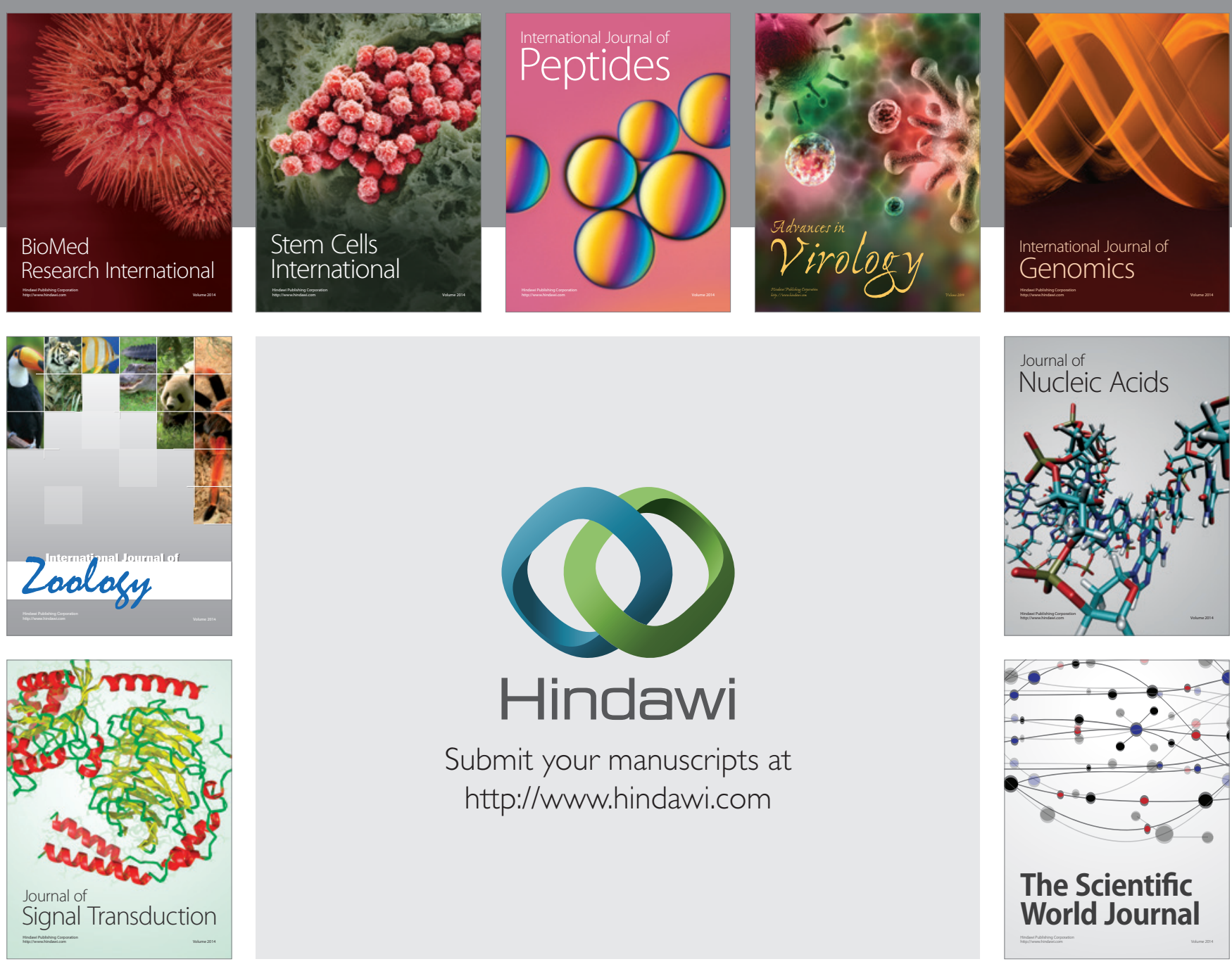

Submit your manuscripts at

http://www.hindawi.com
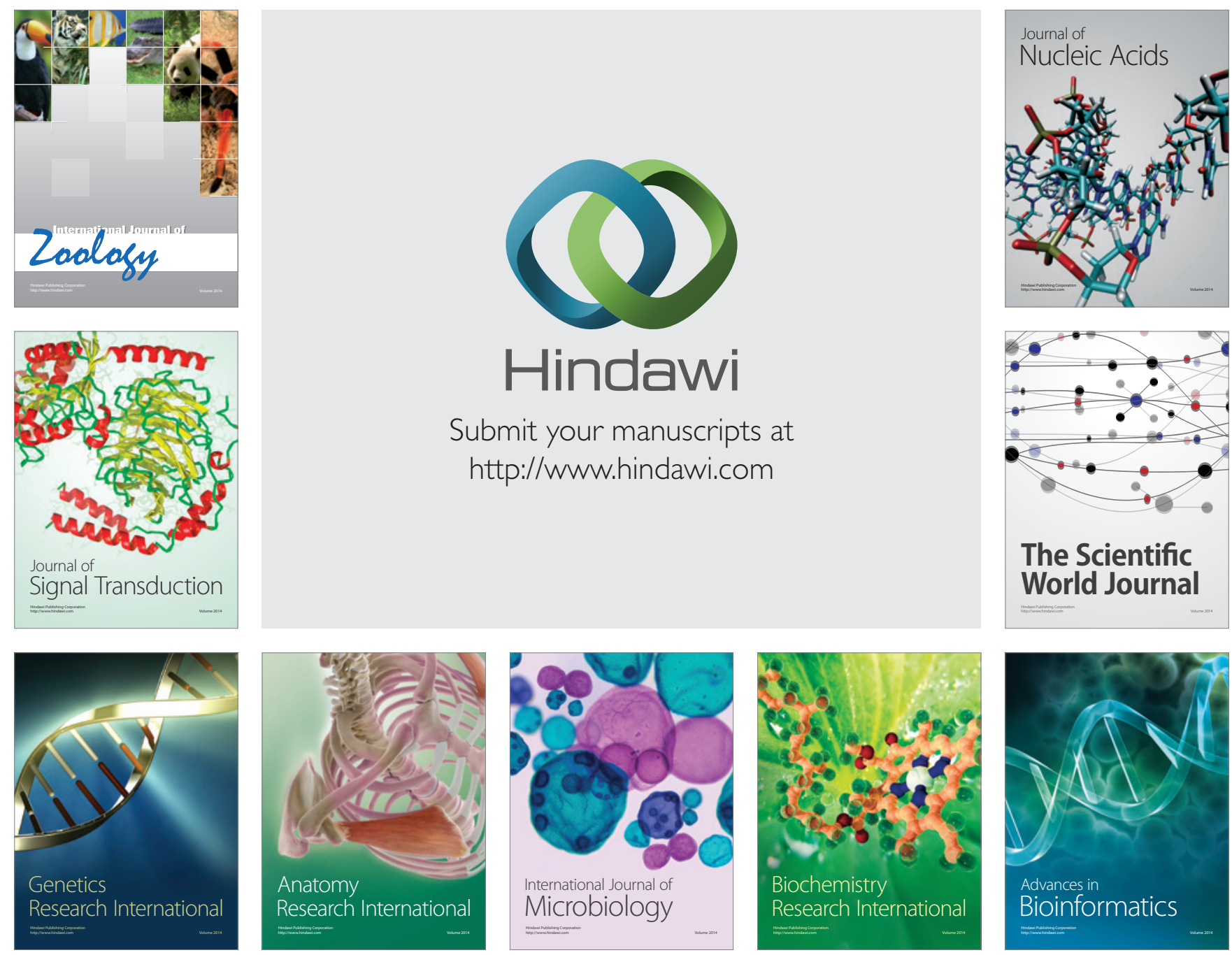

The Scientific World Journal
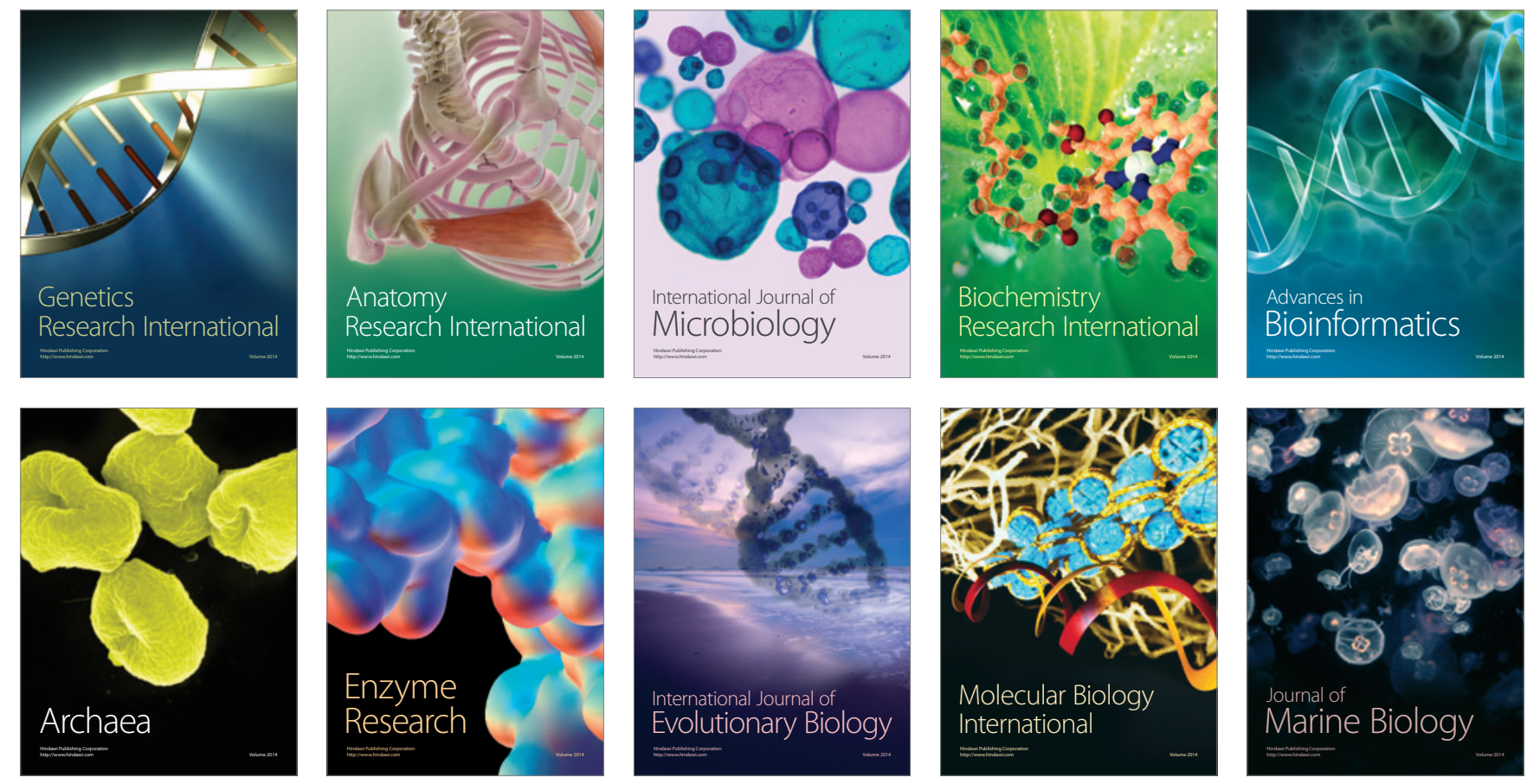